\title{
Effects Of Personality On Conflict Resolution In Student Teams: A Structural Equation Modeling Approach
}

William R. Forrester, Ph.D., Kennesaw State University, USA

Armen Tashchian, Kennesaw State University, USA \& American University of Armenia, Yerevan, Armenia

\begin{abstract}
This paper reports results of a study of the effects of five personality dimensions on conflict resolution preferences in student teams. Two hundred and sixteen students provided self-reports of personality dimensions and conflict styles using the Neo-FFI and ROCI-II scales. Simultaneous effects of five personality dimensions on five conflict resolution styles were modeled using Partial Least Squares (PLS) procedures. Results indicate that agreeableness, openness, conscientiousness, and extroversion impacted conflict resolution styles, whereas neuroticism did not. Findings are discussed along with their implications for team formation, team training, and conflict mediation.
\end{abstract}

Keywords: Personality Dimensions; Conflict Resolution; Structural Equation Modeling

\section{INTRODUCTION}

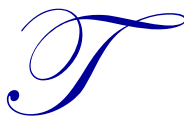

eam activities play an important role in business education and the performance of team activities significantly influences the achievement of learning goals and satisfaction with the learning experience. Teams are ideally suited for activities such as case analyses, role plays, field study projects, and competitive simulations which are critical to developing skills for the modern business workplace and teams allow the achievement of outcomes beyond the capabilities of students working as individuals (McCorkle et. al. 1999; Huff, Cooper, and Jones 2002).

Group activities frequently lead to conflicts among team members. Conflicts can arise from differences in personalities, differences in goals and perspectives, and differences in levels of maturity and commitment (Kirkman, Jones, and Shapiro 2000; Booher 1999). These differences can make conflict resolution difficult. Unless conflicts can be successfully resolved, however, team performance can suffer and with it the quality of learning outcomes and satisfaction with the learning experience (Sikes, Gulbro, and Shonesy 2010).

Unfortunately, knowledge of how to resolve student conflicts is limited. Conflict resolution literature is based on research conducted in work settings rather than in academic contexts. This is problematic because student teams may behave very differently from teams in work settings (Baldwin, Bedell, and Johnson 1997). Student teams are typically much shorter lived than workplace teams since they are formed and dissolved within the limits of the academic quarter or semester systems. Student teams are more frequently formed through self selection than workplace teams which are more likely to be formed on the basis of assignment. Student teams operate without financial incentives which are common in workplace settings.

The literature is also uneven in perspective. Frequently it addresses conflict resolution from the viewpoint of supervisor mediators rather than the viewpoint of the parties involved in the conflict. In addition, much of the work is based on recall of past conflicts rather than conflicts that are currently taking place (Mukhtar and Habib 2010). 
More problematic is the fact that personality differences within teams have received little research attention. This is a significant void in the literature, since personality is central to the functioning of team processes and significantly impacts outcomes (Barrick et.al. 1998). Those efforts that have been made to investigate personality influences have suffered from methodological problems. They have used naïve personality representations (such as dichotomizing subjects as extroverts or introverts) instead of using more conceptually sound personality representations such as the Myers-Briggs or Neo FFI (Mukhtar and Habib 2010; Ergeneli et. al. 2010, ) Where established personality scales have been used, the effects of personality dimensions have been studied separately rather than jointly (Yiu and Lee 2011).

This study seeks to address these limitations by examining the effects of personality on conflict resolution in student teams. Methodological problems of past studies will be addressed by using established measures for personality and conflict resolution styles. The simultaneous influence of multiple personality dimensions will be addressed by using a Partial Least Squares (PLS) modeling approach. Results have the potential to benefit students in terms of conflict anticipation and avoidance, and educators in terms of better guidance for team formation, team training, and conflict mediation.

\section{LITERATURE}

Conflict is defined as a situation in which people are aware that their own wishes are incompatible with the wishes of others or when people become frustrated in their efforts to achieve important goals (Boulding 1962). This definition offers insights into the origins of conflict in student teams. The goals of some team members may differ from those of other members. Students may also have different preferences regarding how work should be conducted and different perceptions regarding desirable work outcomes.

Although unresolved conflicts can undermine team performance, team cohesiveness, and teamwork satisfaction, conflict resolution can positively affect the success of a project if steps are taken to ensure that confrontations are productive. Actions that help individuals to effectively resolve disagreements can ultimately lead to more productive teams (Cloke and Goldsmith 2000).

\section{Conflict Resolution Styles}

Recent research indicates that successfully resolving conflicts requires the use of strategies in line with the predispositions and personalities of the involved parties. Davidson and Biffin (2003) found that conflict resolution through problem-solving, contending, yielding, and avoiding could be explained by two predisposition factors; concern for self and concern for others. Wood and Bell (2008) found that agreeableness and extraversion were significant predictors of conflict resolution preferences in mediation and negotiation situations.

The Rahim model of conflict resolution styles was selected as the basis for representing student conflict resolution preferences. The Rahim model is based on two dimensions representing concern for one's own position and concerns for positions of other parties to the conflict. Based on these two dimensions, five approaches to handling conflict can be identified; integrating, obliging, dominating, avoiding, and compromising (Rahim and Magner 1995). Researchers have described characteristics and behaviors associated with each style and behavior (Booher 1999; Munduate et.al. 1999).

Individuals using an integrating or collaborating style show a high concern for their own positions, but also a high concern for the positions of others. This leads to a preference for collaboration and interacting with others in a win-win manner. Use of an integrating style leads people to speak assertively about their needs, yet search for solutions acceptable to all parties involved. This makes the integrating style the best choice when long-term relationships are involved and when outcomes are too important to compromise.

In the obliging, or accommodating style, people show a low concern for their own position but a high concern for the position of others. This style leads to a preference for accommodation and is often considered a selfsacrificing style that leads to a lose-win outcome. Obliging is common strategy when issues are unimportant and in situations where it is more important to maintain harmony than to achieve a specific outcome. 
In the dominating style, individuals show a high regard for their own positions and low concern for the positions of others. This is a competitive approach that frequently involves the use of power to win. This style leads to a win-lose outcome that is considered appropriate in emergency situations where a specific outcome may require unpopular action.

The avoiding style involves a low concern for one's own position as well as a low regard for the positions of others. This style is equivalent to withdrawal or sidestepping since people using this style do not communicate their needs. It frequently leads to lose-lose outcomes in which neither party's needs are met.

In the compromising style, people show a high concern for their own short-term interests and the short-term interests of other parties, but may not show high regard for the long-term interests of either. This approach leads to outcomes in which neither party loses, but neither party's long-term interests are met. The parties give up something to reach a mutually acceptable solution, however neither party's needs are fully met. Compromise is the preferred approach when issues are important to all parties, but are not considered to be worth jeopardizing longterm relationships.

\section{Personality Dimensions}

The five-factor model is widely accepted as a representation of personality factors that are relevant in business research (Furnham et. al. 2007; Matthews et. al. 2003). This model views personality as consisting of five higher-order components identified as agreeableness, conscientiousness, neuroticism, extraversion, and openness to experience. Research has confirmed that these components have predictive validity in explaining differences in the ways people think, feel, and interact with each other. Dozens of organizational studies have used the five-factor model in recent years and have shown that the model is useful in understanding worker interactions and workplace performance (Huntz and Donovan 2000; Jenh 1999; Mount and Barrick 1998).

The most widely accepted measure of the five-factor dimensions is the Neo Five Factor Inventory (NeoFFI) developed by Costa and McCrae (1992). Their work has identified links between the five dimensions and specific traits. Accordingly, individuals high in Neuroticism are predisposed to insecurity, anxiety, and depression, while those low in Neuroticism are more likely to be calm, patient, and emotionally stable. Those high in Openness tend to be reflective, creative, and comfortable with abstractions while those low in Openness are more conservative in their positions, more practical, and more resistant to change. Individuals high in Extraversion are typically assertive, gregarious, and sociable, while those with low Extraversion tend to be reserved, quiet, or timid. Those high in Agreeableness are likely to be warm, understanding, sympathetic and cooperative in contrast to low Agreeableness individuals who are more likely to be harsh, insincere, rude, and unsympathetic. Finally, people with high levels of Conscientiousness tend to be well organized, dependable, and hard working, and are unlikely to be lazy, disorganized, unreliable, or indecisive.

\section{METHODOLOGY}

Subjects for the study were 216 undergraduate business students (46 percent male) from a southeastern university. The average age of respondents was 27.2 years. Data was collected over a four-semester span in seven different marketing courses. Students comprised 52 teams ranging in size from three to seven members with four being the modal team size. Students participated in the study for course credit.

Data was collected in three phases. During the first phase students were assigned to teams. Team memberships were voluntary; however, in some instances the instructor reassigned students to groups that contained fewer members. After team formation, students provided baseline personality information using the Neo-FiveFactor Inventory (Neo-FFI). It provides a comprehensive sketch of each student's emotional, interpersonal, experiential, attitudinal, and motivational styles (Costa and McCrae 1992). This instrument consists of sixty Likert type items anchored by $1=$ strongly disagree to $5=$ strongly agree. It measures respondents' personality on the five dimensions of agreeableness, conscientiousness, extraversion, neuroticism and openness. A higher score on a scale would indicate a higher level of the specific trait. Table 1 presents the scale mean and Cronbach's alpha for each of the five dimensions, indicating an adequate reliability for the five Neo-FFI scales. 
Table 1

Scale Properties for Measures Used in the Study

\begin{tabular}{lcccc}
\hline & $\begin{array}{c}\text { Number } \\
\text { of Items }\end{array}$ & $\begin{array}{c}\text { Scale } \\
\text { Mean }\end{array}$ & $\begin{array}{c}\text { Item } \\
\text { Mean }\end{array}$ & $\begin{array}{c}\text { Cronbach's } \\
\text { Alpha }\end{array}$ \\
\hline Personality Measures & & & & \\
Agreeableness (AGR) & 12 & 44.81 & 3.73 & 0.701 \\
Conscientiousness (CON) & 12 & 47.25 & 3.94 & 0.818 \\
Extroversion (EXT) & 12 & 45.61 & 3.81 & 0.782 \\
Neuroticism (NEU) & 12 & 27.12 & 2.26 & 0.843 \\
Openness (OPN) & 12 & 41.25 & 3.43 & 0.711 \\
& & & & \\
Conflict Resoulution Styles & & & & \\
Avoiding (AVD) & 6 & 18.03 & 3.01 & 0.825 \\
Compromising (COM) & 4 & 15.68 & 3.92 & 0.705 \\
Dominating (DOM) & 5 & 15.34 & 3.97 & 0.854 \\
Integrating (INT) & 7 & 30.64 & 4.38 & 0.868 \\
Obliging (OBL) & 6 & 22.08 & 3.68 & 0.685 \\
\hline
\end{tabular}

Phase two of data collection took place approximately six weeks later, after teams had sufficient time to work together on a variety of tasks. In phase two, students provided information about various work group characteristics. Using the Work Group Characteristics Inventory, students indicated their perceptions of multiple aspects of job design, interdependence, team composition, work context, and team processes (Campion, Medsker, and Higgs 1993). Students also reported their perceptions of the social and task cohesiveness of the groups (Carless and DePaola 2000).

Finally, at the end of the semester, students indicated their perceptions of various aspects of team effectiveness and the strategies they had used to resolve conflicts that had arisen in their teams. Students reported their conflict resolution preferences using the Rahim Organizational Conflict Inventory (ROCI-II) (Rahim and Magner 1995). The ROCI-II scale is comprised of 28 items which measure five different styles of conflict resolution (avoiding, compromising, dominating, integrating and obliging). These items are scored using a Likerttype response format anchored by $1=$ strongly disagree to $5=$ strongly agree. Cronbach's alphas indicated that internal validity levels were acceptable for the measures of each conflict resolution style in the present sample (Table 1). To be included in the final sample, a student had to complete all three phases of the study.

The relationships among personality variables and conflict resolution styles were tested by using partial least squares structural equation modeling (PLS-SEM) technique. PLS-SEM is similar to multiple regression analysis with the objective of maximizing the explained variance of endogenous latent constructs (dependent variables). Recent mythological advances along with the availability of statistical software, have contributed to the usefulness and popularity of PLS-SEM (Hair et.al. 2011). Since the focus of this study is to predict relationships between personality variables and conflict resolution styles, PLS-SEM was chosen as the appropriate method for analysis. It is well suited for exploratory research with the aim of theory development.

\section{RESULTS}

Figure 1 displays impact of the five personality dimensions on the five conflict resolution strategies. The model hypothesizes that each personality dimension has a direct impact on each of the resolution strategies. Testing the full model revealed that of the 25 paths connecting personality to conflict resolution strategies only nine paths were statistically significant. Figure 2 displays the significant paths among the personality measures and conflict resolution styles along with the path coefficients. 


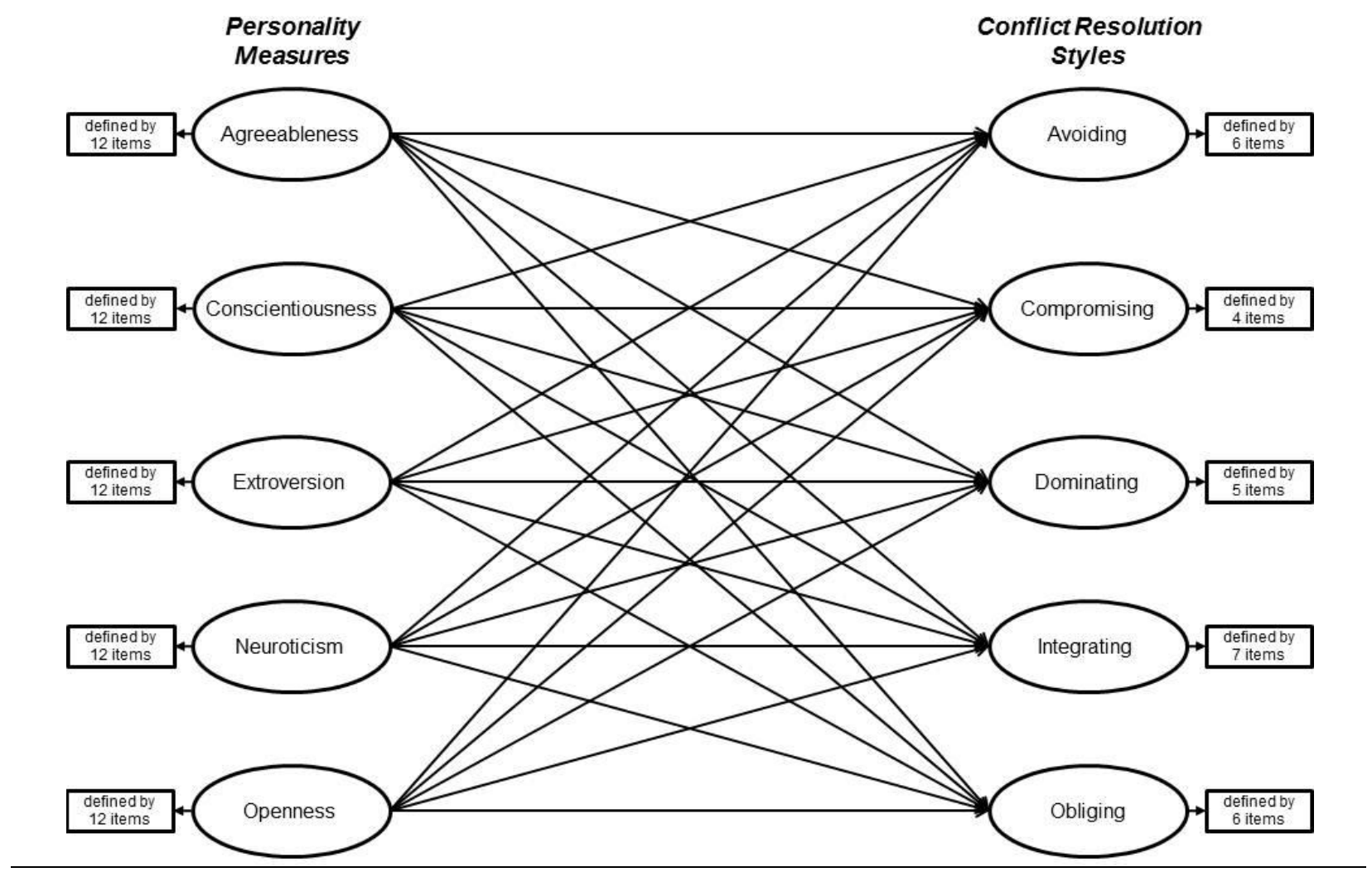

Figure 1

Hypothesized Relationships among Personality Measures and Conflict Resolution Styles

As can be seen from the analysis, neuroticism as a personality dimension had no impact on any of the conflict resolution strategies. It appears that individuals who are worriers, feel inferior to others, and are often isolated, have no learned mechanisms for resolving conflicts with their team members.

Of the other four personality measures, conscientiousness was related to respondents' integrating conflict resolution strategies $(\mathrm{CON} \rightarrow \mathrm{INT}=0.162, \mathrm{t}=2.55, \mathrm{p}<0.01)$. This relationship implies that individuals who are methodical and perform tasks conscientiously are willing to bring all concerns out in the open and collaborate with team members to find win-win solutions.

Individuals high in extroversion enjoy talking to people, are active, energetic, cheerful and high spirited. These individuals exercise the dominating approach to conflict resolution when dealing with team members (EXT $\rightarrow \mathrm{DOM}=0.296, \mathrm{t}=3.32, \mathrm{p}<0.01)$. Specifically, they use their influence, authority, and expertise to get their ideas accepted and use their power to win and to have decisions in their favor.

Agreeableness was positively related to all conflict resolution strategies except dominating. Thus, agreeable individuals appear to be most flexible in the management and resolution of conflict. For example, courteous individuals who avoid arguments and cooperate rather than compete with others would also be likely to find a middle course to resolve impasses, and negotiate with team members through compromise $(\mathrm{AGR} \rightarrow \mathrm{COM}=$ $0.438, \mathrm{t}=6.83, \mathrm{p}<0.01)$. They are also likely to avoid open discussions and unpleasant exchanges, and being "put on the spot" (AGR $\rightarrow$ AVD $=0.263, \mathrm{t}=3.10, \mathrm{p}<0.01)$. Furthermore, they try to investigate issues with their team members, work to find solutions and bring all concern out in the open - a collaborative approach to conflict resolution $(\mathrm{AGR} \rightarrow \mathrm{INT}=0.303, \mathrm{t}=4.79, \mathrm{p}<0.01)$. Finally, they are willing to accommodate by giving in to wishes of team members, go along with suggestions of the group, and allow concessions to fellow team members $(\mathrm{AGR} \rightarrow \mathrm{OBL}=0.252, \mathrm{t}=2.19, \mathrm{p}<0.01)$. 


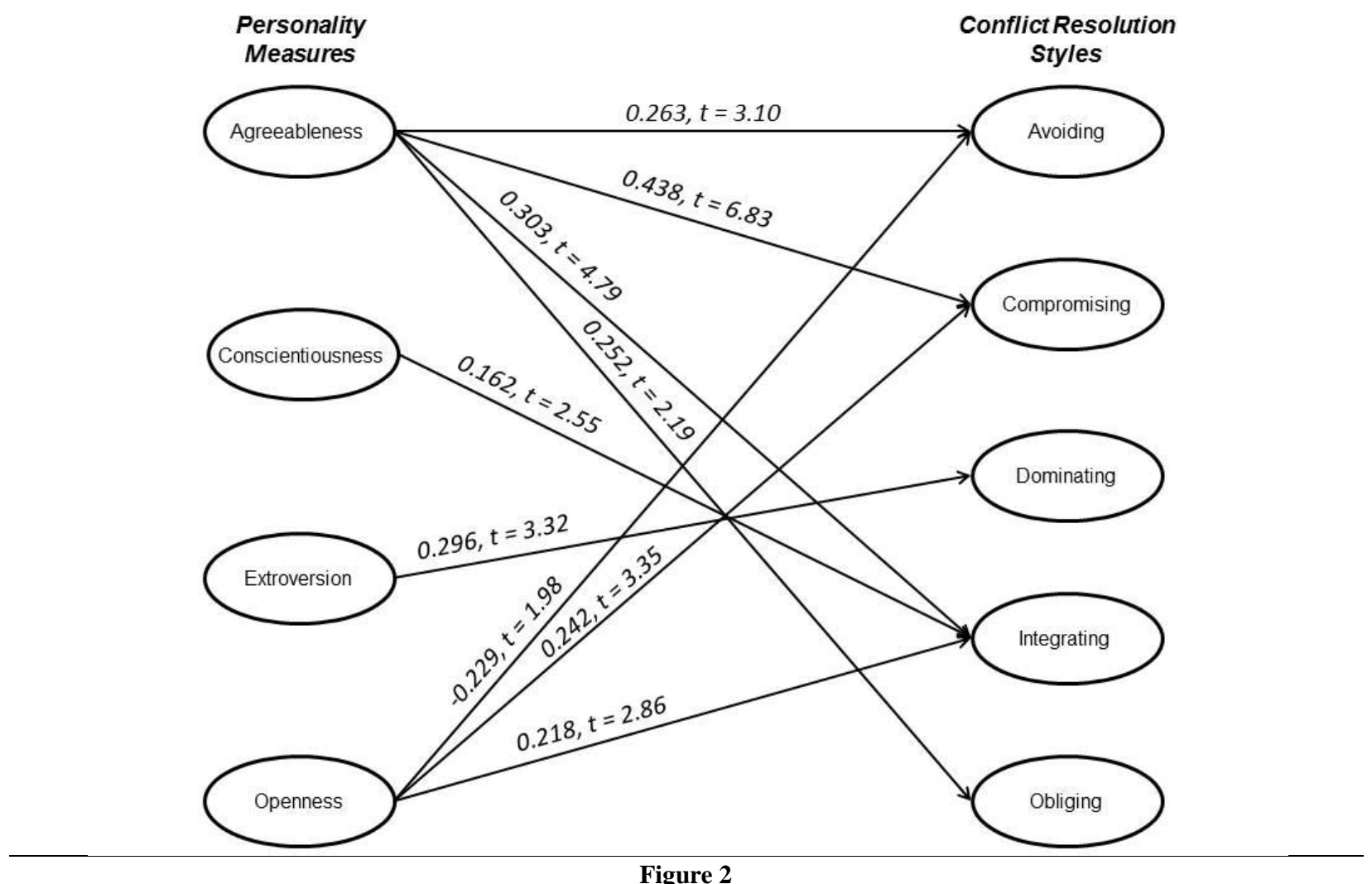

Personality Factors Influencing Conflict Resolution Styles in Student Teams

Individuals high on openness are receptive to new ideas, have intellectual curiosity, and enjoy theories and abstract ideas. Openness is positivity related to finding a middle course of give-and-take to resolve impasses and find compromise (OPN $\rightarrow \mathrm{COM}=0.242, \mathrm{t}=3.35, \mathrm{P}<0.01)$. Open individuals also try to investigate issues and integrate their ideas with group's viewpoints in order to find win-win solutions (OPN $\rightarrow$ INT $=0.218, t=2.86, p<$ 0.01). However, unlike agreeable individuals, they welcome open discussions and do not avoid encounters with team members. They bring issues into the open in order to find mutually acceptable solutions (OPN $\rightarrow-0.229, \mathrm{t}=$ $1.98, \mathrm{p}<0.05)$.

\section{SUMMARY AND CONCLUSIONS}

Findings of this study offer benefits to both students and business educators. Prior research has shown that increased awareness of conflict resolution preferences leads to greater tolerance (Friedman et. al. 2000). Students who are aware of links between personality and resolution styles are better able to anticipate behaviors aimed at conflict resolution. They are also more likely to interpret these behaviors favorably. For example, students who realize that extroverts prefer the dominating style, are better able to interpret domineering as an effort at problem solution, and are more tolerant of dominating behavior. In this way, personality differences are less likely to trigger emotional reactions which compound conflicts and make resolution more difficult.

Results may also be helpful to business educators who are responsible for providing teams with support, guiding team processes, and mediating team conflicts. By being aware of differences in team member personalities, educators are able to train students to anticipate, recognize, and adapt to personality linked behaviors. This means that they are also able to recommend resolution approaches that are likely to be acceptable to all parties. 
Findings of the study also have career implications for students entering professional life. Business professionals interact with a broad array of personality types in situations where conflict arises and must be resolved. Marketers, for example, must resolve conflicts with customers, channel intermediaries, and support service providers. In addition, they must resolve conflicts with personnel from non-marketing functions within their own organizations. Awareness of personality-linked resolution preferences enables them to be more tolerant, more adaptable, and more effective.

While findings are consistent with results of prior research, this study extends the literature by overcoming some of the artificiality of earlier methodologies. This study examined preferences of students for resolving conflicts that arose in actual teams instead of contrived situations or scripted scenarios. In addition, this study examined effects of personality on conflict resolution simultaneously rather than the previous approach of examining them in isolation.

The reader should be mindful of certain limitations when interpreting the findings of this study. The study did not distinguish between minor conflicts, and those more seriousness in scope, nor did it distinguish between task-oriented and people-oriented conflicts. An additional limitation is that no consideration was given to the effectiveness of preferred conflict resolution styles. These issues should be considered in future research.

\section{AUTHOR INFORMATION}

William Forrester received his Ph.D. in Marketing in 1986 from the University of Tennessee. He currently works as Professor of Marketing in the Coles College of Business at Kennesaw State University. He has published in the Journal of Academy of Marketing Science, the Journal of Economic Psychology, and the Journal of Applied Business Research, and numerous other outlets. E-mail: wforrest@kennesaw.edu

Armen Tashchian is Professor of Marketing in the Coles College of Business at Kennesaw State University. He received his Ph.D. in Marketing from the University of Texas in 1980. He has published in numerous academic journals including Journal of Marketing, the Journal of Marketing Research, and the Journal of Academy of marketing Science. E-mail: atashchi@kennesaw.edu (Corresponding author)

\section{REFERENCES}

1. Baldwin, Timothy T., Michael D. Bedell and Johnathan L. Johnson (1997), "The social fabric of a teambased M.B.A. program: Network effects on student satisfaction and performance", Academy of Management Journal, Volume 40, Issue 6, 1369-1397.

2. Barrick, Murray R., Greg L. Stewart, Mitchell J. Neubert, and Michael K. Mount. 1998. Relating member ability and personality to work-team processes and team effectiveness. Journal of Applied Psychology 83 (3) (06): 377-91.

3. $\quad$ Booher, Dianna. 1999. Resolving conflict. Executive Excellence 16 (5) (05): 5.

4. Boulding, Kenneth (1962) Conflict and Defense. New York, NY: Harper and Row.

5. Campion, Michael A, Gina J. Medsker, and A. Catherine Higgs (1993), "Relations between Work Group Characteristics and Effectiveness: Implications for Designing Effective Work Groups.” Personnel Psychology, Volume 46, 823-847.

6. Carless, Sally A. and Caroline DePaola (2000), "The Measurement of Cohesion in Work Teams." Small Group Research, Volume 31, Issue 1, 71-88.

7. Costa, Paul T., Jr. and Robert R. McCrae (1992), Neo PI-R and Neo-FFI Professional Manual. Odessa, FL: Psychological Assessment Resources, Inc.

8. Cloke, Kenneth and Joan Goldsmith (2000), "Conflict resolution that reaps great rewards", Journal for Quality and Participation, Volume 23, Issue 3, 27-30.

9. Davidson, J., and F. Biffin. 2003. The influence of person and situation factors in the choice of conflict resolution style. Wiley-Blackwell.

10. Ergeneli, Azize, Selin Metin Camgoz, and Pinar Bayhan Karapinar. 2010. The relationship between selfefficacy and conflict-handling styles in terms of relative authority positions of the two parties. Social Behavior \& Personality: An International Journal 38 (1) (02): 13-28. 
11. Friedman, R.A., Tidd, S.T., Currall, S.C. and Tsai, J.C. (2000), "What goes around comes around: the impact of personal conflict style on work conflict and stress", International Journal of Conflict Management, Vol. 11, pp. 32-55.

12. Furnham, Adrian, Georgia Dissou, Peter Sloan, and Tomas Chamorro-Premuzic. 2007. Personality and intelligence in business people: A study of two personality and two intelligence measures. Journal of Business \& Psychology 22 (1): 99-109.

13. Hair, J., C. Ringle, and M. Sarstedt (2011), PLS-SEM: Indeed a silver bullet. Journal of Marketing Theory and Practice, 19 (2), 139-151.

14. Huff, Lenard C., Joanne Cooper, and Wayne Jones. 2002. The development and consequences of trust in student project groups. Journal of Marketing Education 24 (1) (04): 24-34.

15. Huntz, E., \& Donovan, J. (2000). Personality and job performance. The big five resulted. Journal of Applied Psychology 85 (4): 869-879.

16. Jehn, Karen A. (1999), "Diversity, conflict, and team performance: Summary of a program of research." Performance Improvement Quarterly 12 (1): 6-19.

17. Kirkman, Bradley L., Robert G. Jones, and Debra L. Shapiro. 2000. Why do employees resist teams? Examining the "resistance barrier" to work team effectiveness. International Journal of Conflict Management 11 (1) (01): 74-92.

18. Matthews, G., Deary, I., \& Whiteman, M. (2003). Personality traits. Cambridge: Cambridge University Press.

19. McCorkle, Denny E., James Reardon, Joe F. Alexander, Nathan D. Kling, Robert C. Harris, and R. V. Iyer. 1999. Undergraduate marketing students, group projects, and teamwork: The good, the bad, and the ugly? Journal of Marketing Education 21 (2) (08): 106-117.

20. Mount, Michael K., and Murray R. Barrick. 1998. Five reasons why the "big five" article has been frequently cited. Personnel Psychology 51 (4) (Winter 98): 849-857.

21. Mukhtar, Sabina, and Muhammad Nauman Habib. 2010. Private sector managers approach to conflict management: A study of relationships between conflict management styles and personality type. Interdisciplinary Journal of Contemporary Research in Business 2 (1) (05): 304-312.

22. Munduate, Lourdes, Juan Ganaza, José M. Peiró, and Martin Euwema. 1999. Patterns of styles in conflict management and effectiveness. International Journal of Conflict Management 10 (1) (01): 5-24.

23. Rahim, M. Afzalur and Nace R. Magner (1995), "Confirmatory factor analysis of the styles of handling interpersonal conflict: First-order factor model and its invariance across groups." Journal of Applied Psychology, 80 (1): 122-132.

24. Sikes, Brittany, Robert D Gulbro, and Linda Shonesy. 2010. Conflict in work teams. Proceedings of the Academy of Organizational Culture, Communications, and Conflict 15 (1): 15-19.

25. Wood, Valerie Ford, and Paul A. Bell. 2008. Predicting interpersonal conflict resolution styles from personality characteristics. Personality \& Individual Differences 45 (2) (07/15): 126-31.

26. Yiu, Tak Wing, and Hung Kei Lee. 2011. How do personality traits affect construction dispute negotiation? Study of big five personality model. Journal of Construction Engineering \& Management 137 (3) (03): 169-178. 